Onur Çavuşoğlu

Hakan Gürün

DOI: $10.21278 /$ TOF.41105

ISSN 1333-1124

eISSN 1849-1391

\title{
THE RELATIONSHIP OF BURR HEIGHT AND BLANKING FORCE WITH CLEARANCE IN THE BLANKING PROCESS OF AA5754 ALUMINIUM ALLOY
}

\begin{abstract}
Summary
The effect of clearance and sheet thickness in the AA5754 sheet material blanking process on the burr formation and blanking force was examined experimentally. Measurements of the burr height and blanking force were performed in a modular die with six different clearance values $(8 \%, 10 \%, 12 \%, 14 \%, 16 \%$ and $18 \%)$ by applying the blanking process to the AA5754 sheet metal of $1 \mathrm{~mm}$ and $2 \mathrm{~mm}$ in thickness. The influence rate of parameters affecting the burr height, the blanking force, and the mathematical relationship between them were identified by using the analysis of variance (ANOVA) and the regression analysis. Thus, it was determined that the burr formation increased with increased clearance and that the blanking force was not affected in the same proportion. In addition, it was found that the sheet thickness and clearance affected the burr formation at rates of $23.24 \%$ and $76.15 \%$, respectively; on the other hand, the sheet thickness and clearance affected the blanking force at rates of $99.72 \%$ and $0.24 \%$, respectively.
\end{abstract}

Key words: $\quad$ clearance, blanking, ANOVA, AA5754, regression analysis

\section{Introduction}

Aluminum alloys are one of the most widely used materials in the automotive and the aerospace industry due to their good properties (density, resistance, and formability) and to results of studies on the reduction in fuel consumption achieved by decreasing the vehicle weight [1].

Blanking process is often a preferred method among processes of sheet metal forming. The blanking process occurs in a fractured way unlike the elastic deformation, plastic deformation, and other forming processes. Therefore, the purpose of blanking process is to provide sheet separation in an intended shape besides deformation of the material. During the blanking process, clearance, punch speed, mechanical properties of material, tool geometry, and the sheet thickness affect the required blanking force and the zones of blanked product shown in Figure 1 [2]. 


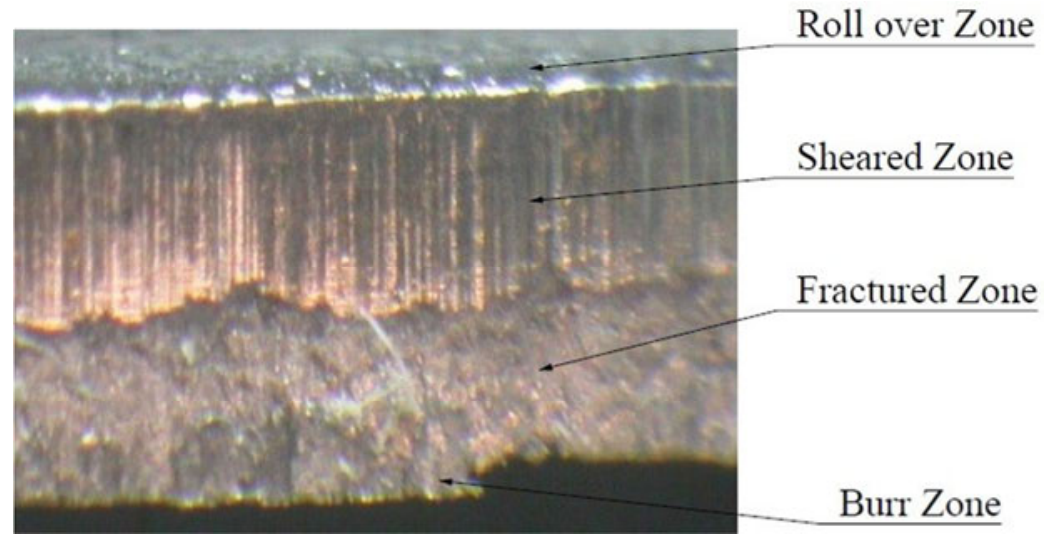

Fig. 1 Blanked product surface

The product quality is proportional to the burr height. A certain amount of clearance between the punch and the die must be left in order to carry out the blanking process. By playing an important role in the blanking process, the amount of clearance affects the burr height and the quality of the product obtained from the blanking process. Therefore, the optimal clearance value should be selected. The amount of clearance varies, depending on the sheet thickness and mechanical properties of the material [3-4]. In case the clearance value is below the optimal value, the blanking force and stress on the die surfaces will increase and the die life will decrease. On the other hand, if the clearance value is above the optimal value, this will lead to an increase in burr formation on the product [3].

Researchers have already done a great number of studies on the blanking process. When these studies are examined, experimental studies investigating the blanking process and analytical studies based on the finite element method attract attention [2-7]. In these studies it was shown that clearance was directly related to the product quality. The study carried out by finite element method is said to be quite consistent with experimental studies. In addition, based on experimental results from the literature, estimations about the blanking process and the blanked product were done by using artificial intelligence [6].

In this study, the relation between clearance, blanking force and the amount of burrs formation on the product during the blanking process was investigated. Blanking experiments with the AA5754 sheet metal of $1 \mathrm{~mm}$ and $2 \mathrm{~mm}$ in thickness were carried out in a modular die which had six different clearance values. The burr heights of products were measured using an optical microscope. The blanking forces were found with a load cell depending on the die. Unlike other studies, the influence rates of clearance and sheet thickness on the amount of burr and the blanking force were identified. The relation between clearance and the burr height and that between clearance and the blanking force were determined mathematically by carrying out regression analysis.

\section{Material and Method}

\subsection{Material}

Aluminum alloys are used in the fabrication of precision parts used in the automotive and aerospace industries. Thus, the AA5754 material, a kind of aluminum alloy, in sheets of 1 $\mathrm{mm}$ and $2 \mathrm{~mm}$ in thickness, was used in this research. The chemical composition and mechanical properties of the AA5754 sheet material are given in Table 1 and Table 2. Blanking experiments were performed by using a modular test die in a hydraulic press. A flat punch (Ø $20 \mathrm{~mm})$ was used. 

of AA5754 Aluminum Alloy

Table 1 Chemical composition of AA5754 (weight percent, \%)

\begin{tabular}{ccccccccc}
\hline Material & $\mathrm{Mg}$ & $\mathrm{Mn}$ & $\mathrm{Si}$ & $\mathrm{Fe}$ & $\mathrm{Ti}$ & $\mathrm{Zn}$ & $\mathrm{Cu}$ & $\mathrm{Cr}$ \\
\hline AA5754 & 2.76 & 0.27 & 0.20 & 0.34 & 0.01 & 0.01 & 0.02 & 0.02 \\
\hline
\end{tabular}

Table 2 Mechanical properties of AA5754

\begin{tabular}{ccccccc}
\hline Material & $\begin{array}{c}\text { Tensile } \\
\text { Strength }\end{array}$ & $\begin{array}{c}\text { Yield } \\
\text { Strength }\end{array}$ & Elongation & $\begin{array}{c}\text { Young's } \\
\text { Modulus }\end{array}$ & $\begin{array}{c}\text { Poisson } \\
\text { Ratio }\end{array}$ & Density \\
\hline AA5754 & $225 \mathrm{MPa}$ & $148 \mathrm{MPa}$ & $\% 18.5$ & $68 \mathrm{GPa}$ & 0.33 & $2.67 \mathrm{gr} / \mathrm{cm}^{3}$ \\
\hline
\end{tabular}

During the blanking experiments, the blanking force by means of the load cell data reading card, amplifiers, and data display software. Having a $2000 \mathrm{data} / \mathrm{sec}$ reading data speed, a Kistler branded load cell with a capacity of $120000 \mathrm{~N}$ was used for the force measurements and an optical microscope having a magnification of 40 times for the measurement of burr height.

\subsection{Method}

Blanking experiments were carried out by using two different values of sheet thickness $(1 \mathrm{~mm}$ and $2 \mathrm{~mm})$ and 6 different clearance values $(8 \%, 10 \%, 12 \%, 14 \%, 16 \%$ and $18 \%)$. The selected punch velocity was $0.75 \mathrm{~m} / \mathrm{min}$. The average results calculated from five repeated experiments were used to reduce the error margin. Burr heights of samples obtained from the experiments were measured by an optical microscope. During the blanking experiments, the blanking force was determined by using a load cell. A schematic diagram of the experimental setup used in the study is given in Figure 2.

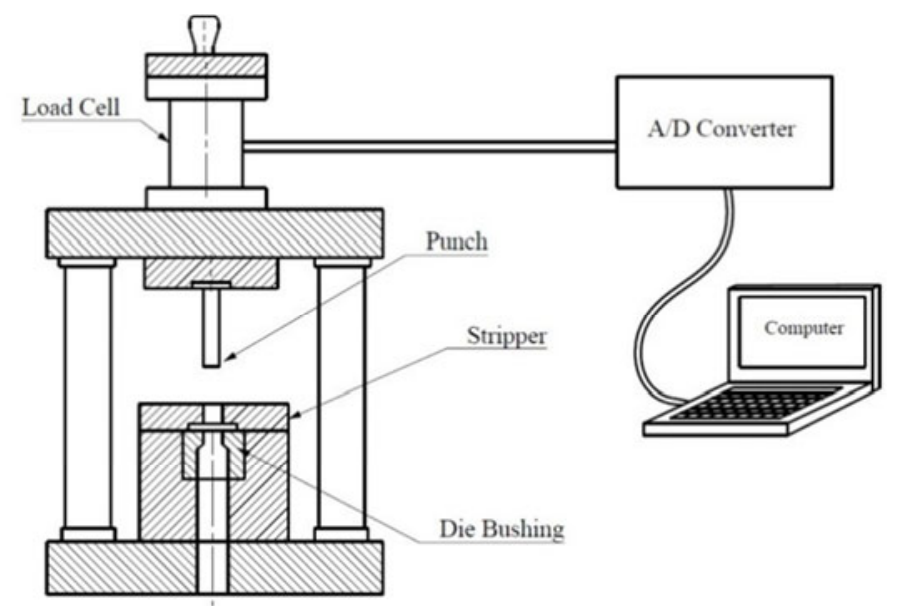

Fig. 2 Schematic overview of experimental setup

The analysis of variance (ANOVA) and regression analysis were performed to examine the relation between clearance and burr height and between clearance and blanking force. Blanking parameters and their levels are given in Table 3.

Table 3 Blanking parameters and their levels

\begin{tabular}{ccc}
\hline Level & Thickness $(\mathrm{mm})$ & Clearance $(\%)$ \\
\hline 1 & 1 & 8 \\
2 & 2 & 10 \\
3 & & 12 \\
4 & & 14 \\
5 & & 16 \\
6 & & 18 \\
\hline
\end{tabular}




\section{Results and Discussion}

\subsection{Burr Height}

In the sheet metal blanking process, the excess material called burr occurs on the product in the opposite direction of material flow. The amount of burr affects directly the product quality. In previous studies it has been reported that the burr height is lower on soft materials than on hard materials going through the blanking process at the same clearance [3]. This phenomenon increases in importance when soft and ductile materials such as aluminium alloys are blanked. Therefore, the burr which will occur on the product to be produced by the blanking process should be within acceptable limits [5]. Burr heights on the samples obtained from the blanking experiments were determined in our study. Experimental data were analysed by the analysis of variance (ANOVA) to evaluate the effects of clearance and sheet thickness on the burr height.

The analysis results show that the sheet thickness and clearance have an effect on the burr height $(\mathrm{P}<0.05)$. When contribution $(\mathrm{C})$ values were analysed, it was determined that clearance affected the burr height on the product during the blanking process at a rate of 76.25 $\%$ and the sheet thickness at a rate of $23.24 \%$. The analysis of variance (ANOVA) results are given in Table 4.

Table 4 Two-way ANOVA: burr height versus thickness; clearance

\begin{tabular}{lllllcc}
\hline Source & $\begin{array}{l}\text { Degree of } \\
\text { Freedom }\end{array}$ & Sum of Square & Mean Square & F-Value & P-Value & Contribution \\
\hline Thickness & 2 & 0.0015339 & 0.0007670 & 193.91 & 0.001 & $23.24 \%$ \\
Clearance & 5 & 0.0050245 & 0.0010049 & 254.07 & 0.001 & $76.15 \%$ \\
Error & 10 & 0.0000396 & 0.0000040 & & $0.60 \%$ \\
Total & 17 & 0.0065980 & & & \\
\hline $\mathrm{S}=0.001989$ & $\mathrm{R}-\mathrm{Sq}=99.40 \%$ & $\mathrm{R}-\mathrm{Sq}(\mathrm{adj})=98.98 \%$ & & & \\
\hline
\end{tabular}

Table 5 Regression analysis result for the burr height

\begin{tabular}{lllll}
\hline \multicolumn{5}{l}{ The regression equation is Burr Height $=0.0258+0.485$ Clearance +0.0226 Thickness } \\
\hline Predictor & Coefficient & SE Coefficient & $\mathrm{T}$ & $\mathrm{P}$ \\
Constant & 0.025763 & 0.003630 & 7.10 & 0.001 \\
Clearance & 0.48508 & 0.01974 & 24.57 & 0.001 \\
Thickness & 0.022612 & 0.001652 & 13.69 & 0.001 \\
\hline $\mathrm{S}=0.00286078$ & $\mathrm{R}-\mathrm{Sq}=98.1 \%$ & $\mathrm{R}-\mathrm{Sq}(\mathrm{adj})=97.9 \%$ & & \\
\hline
\end{tabular}

In addition, regression analysis was performed to determine the relationship between clearance and burr height. Regression analysis results are given in Table 5. According to the results of regression analysis, data obtained by making the burr height estimations are compared with the experimental results. According to equations obtained from the regression analysis, the performed estimations were also consistent with the experimental results. It was determined that the regression equation given in Table 5 could be used in the blanking process of AA5754 sheet materials to identify the burr height.

It is known that the burr formation increases with an increase in burr height [6]. When the relationships, between the burr height and the clearance given in Figures 3 and 4 were examined, it was determined that the burr height also increased with an increasing clearance. 


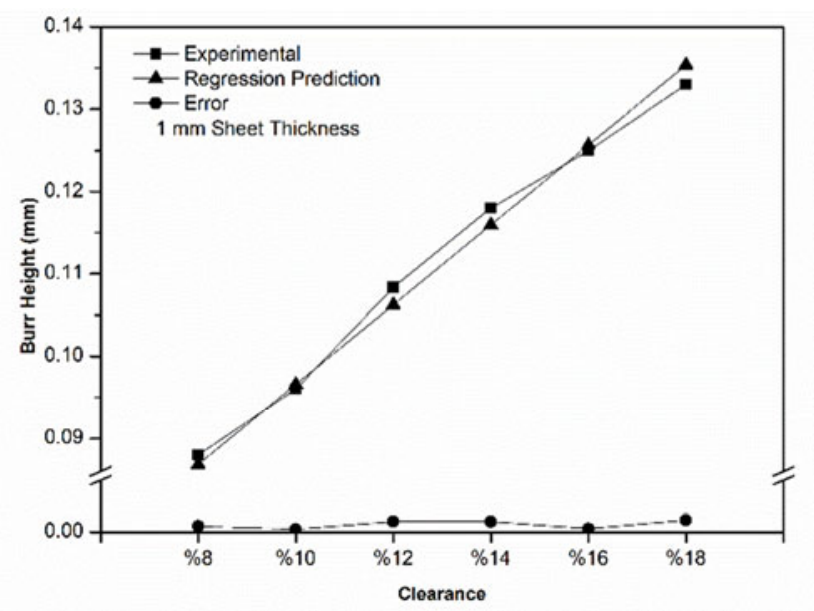

Fig. 3 Clearance - burr height relation for $1 \mathrm{~mm}$ sheet thickness

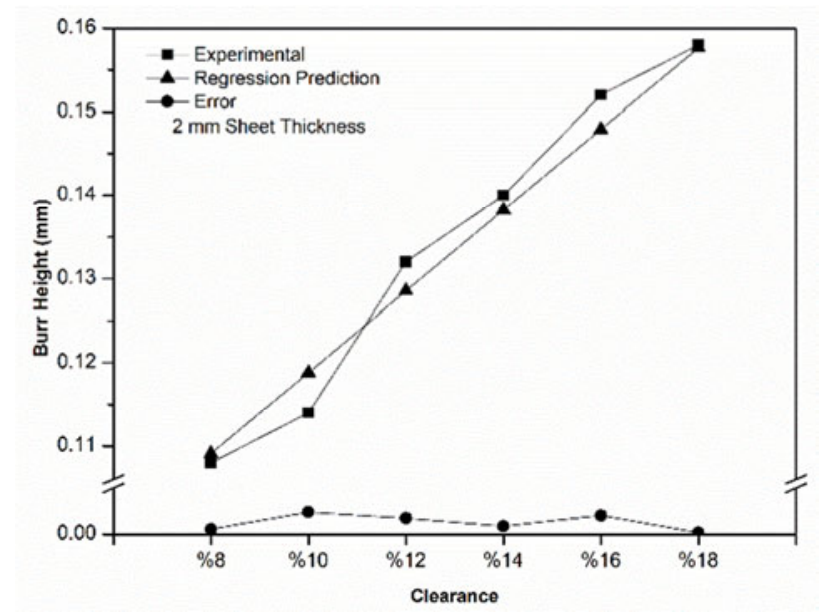

Fig. 4 Clearance - burr height relation for $2 \mathrm{~mm}$ sheet thickness

\subsection{Blanking Force}

Deformation process must be performed by a force having the value above the breaking strength of the material to enable blanking during the sheet metal blanking process. For this reason, the blanking force is the main factor in the sheet metal process. In our experiments, the blanking process was performed with a punch of ø $20 \mathrm{~mm}$ in diameter. Analysis of variance (ANOVA) was applied to examine the effects of sheet thickness and clearance on the blanking process. Analysis of variance (ANOVA) results are given in Table 6.

Table 6 Two-way ANOVA: blanking force versus thickness; clearance

\begin{tabular}{llllllc}
\hline Source & $\begin{array}{l}\text { Degree of } \\
\text { Freedom }\end{array}$ & Sum of Square & Mean Square & F-Value & P-Value & Contribution \\
\hline Thickness & 2 & 1700941411 & 850470706 & 17281.7 & 0.001 & $99.72 \%$ \\
Clearance & 5 & 4169694 & 833939 & 16.95 & 0.001 & $0.24 \%$ \\
Error & 10 & 492122 & 49212 & & & $0.02 \%$ \\
Total & 17 & 1705603228 & & & & \\
\hline $\mathrm{S}=221.8$ & $\mathrm{R}-\mathrm{Sq}=99.97 \%$ & $\mathrm{R}-\mathrm{Sq}(\mathrm{adj})=99.94 \%$ & & & \\
\hline
\end{tabular}

In the wake of the analysis results, both factors were found to affect the blanking force $(\mathrm{P}<0.05)$. It was determined that the influence rate of clearance was $0.24 \%$ and that of the 
sheet thickness $99.72 \%$. Accordingly, the influence of blanking forces on the clearance of blanking was found to be small.

Regression analysis was carried out based on the results of blanking forces related to the clearance of blanking obtained from the load cell during experiments. Regression analysis results are given in Table 7.

Table 7 Regression analysis results for blanking force

\begin{tabular}{|c|c|c|c|c|}
\hline \multicolumn{5}{|c|}{ The regression equation is Blanking Force $=10501-11367$ Clearance +23162 Thickness } \\
\hline Predictor & Coefficient & SE Coefficient & $\mathrm{T}$ & $\mathrm{P}$ \\
\hline Constant & 10501 & 3168 & 3.31 & 0.005 \\
\hline Clearance & -11367 & 17229 & -0.66 & 0.519 \\
\hline Thickness & 23162 & 1441 & 16.07 & 0.000 \\
\hline $\mathrm{S}=0.00286078$ & $\mathrm{R}-\mathrm{Sq}=98.1 \%$ & $\mathrm{R}-\mathrm{Sq}(\mathrm{adj})=97.9 \%$ & & \\
\hline
\end{tabular}

The blanking force equation depending on the sheet thickness and clearance is derived. Blanking force estimations obtained from this equation are given in Figures 5 and 6 in comparison with experimental data.

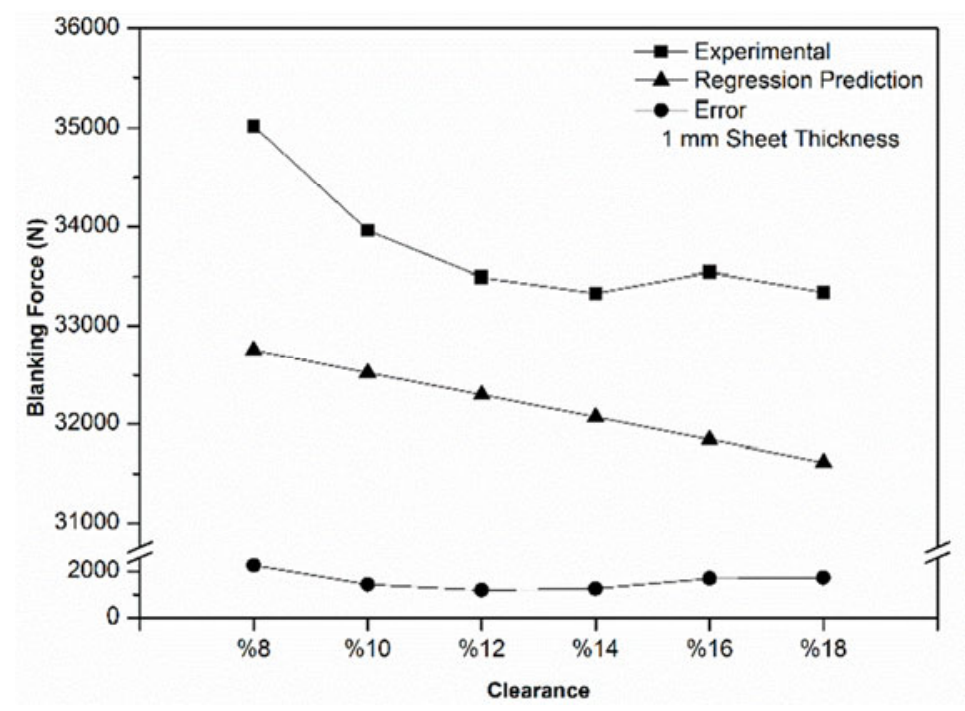

Fig. 5 Clearance - blanking force relation for $1 \mathrm{~mm}$ sheet thickness

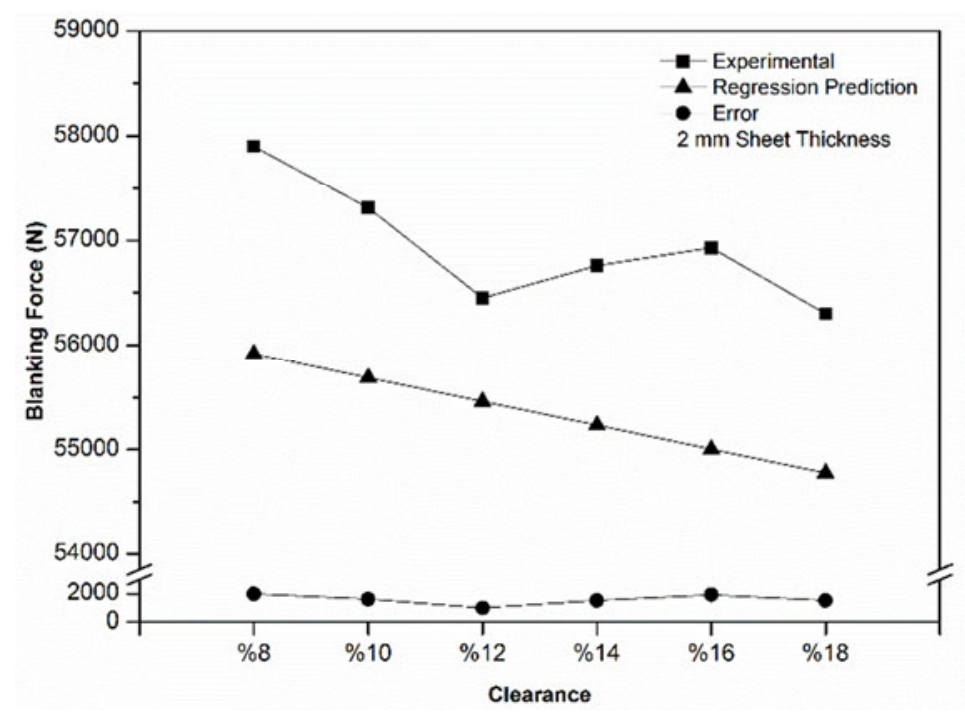

Fig. 6 Clearance - blanking force relation for $2 \mathrm{~mm}$ sheet thickness 
When previous studies are concerned, the study conducted by Tekiner et al [3], showed that the blanking forces changed significantly with an increase in clearance. However, in the studies conducted by Shuqin et al. and Gang et al. [4,7], it is seen that the blanking force decreases slightly with an increase in clearance. When the graphics of the relation between the clearance and the blanking force obtained from experimental results was examined, it was determined that blanking forces occurring through an increase in clearance did not change significantly. Therefore, it is thought that the clearance of blanking does not affect the blanking force occurring in the blanking process of soft materials such aluminum. The influence rate of clearance obtained from the analysis of variance (ANOVA) supports this conclusion. Also, it is noted that blanking force estimations carried out with respect to the equation obtained from the regression analysis are consistent with experimental results. Therefore, it was understood that this equation can be used to estimate the blanking force.

\section{Conclusions}

In this study, the relationship of clearance of blanking, sheet thickness, burr length, and blanking force was investigated on the AA5754 material. The following results were obtained.

- It was determined that the sheet thickness affected the burr formation, at a rate of $23.24 \%$ and the clearance of blanking at a rate of $76.15 \%$. Based on the experiments conducted with two values of sheet thickness, it was determined that the burr height increased with an increase in clearance. Minimum burr formation was obtained with the minimum clearance value of $8 \%$. Therefore, the minimum clearance of blanking results in lower burr and a high quality product. Estimations carried out in the wake of regression analysis were found to be consistent with experimental results. The burr height of AA5754 sheet material can be estimated through the following equation: Burr Height $=0.0258$ +0.485 Clearance +0.0226 Thickness.

- The influence rates of sheet thickness and clearance were determined. The sheet thickness had an influence rate of $99.72 \%$; clearance was not particularly effective with an influence rate of $0.24 \%$. It can be seen that the blanking force was not affected by an increase in clearance in both cases of the sheet thickness. It was found that blanking force estimations carried out with respect to the equation obtained from the regression analysis are consistent (the error rate is negligible) with experimental results. Blanking forces for AA5754 sheet materials can be estimated through the following equation: Blanking Force $=$ 10501 - 11367 Clearance +23162 Thickness.

For future research work, this study can be expanded by developing a general mathematical model for the burr height-blanking force relationship by using blanking parameters of different type aluminum alloy sheets that have various shear strength and by investigating punch velocity effects.

\section{REFERENCES}

[1] Sarkar, J., Kutty, T.R.G., Conlon, K.T., Wilkinson, D.S., Embury, J.D., Lloyd, D.J., Tensile and bending properties of AA5754 aluminum alloys, Materials Science and Engineering, 2001, A316, pp. 52-59. DOI: $10.1016 / \mathrm{S} 0921-5093(01) 01226-6$

[2] Samuel, M., FEM simulations and experimental analysis of parameters of influence in the blanking process, Journal of Materials Processing Technology, 1998, 84, pp. 97-106.

DOI: 10.1016/S0924-0136(98)00083-1 
[3] Tekiner, Z., Nalbant, M., Gürün, H., An experimental study for the effect of different clearances on burr, smooth-sheared and blanking force on aluminum sheet metal, 2006, Materials and Design, 27, pp. 11341138. DOI: 10.1016/j.matdes.2005.03.013

[4] Shuqin, X., Hoogen, M., Pyttel T., Hoffmann, H., FEM simulation and experimental research on the AlMg4.5Mn0.4 sheet blanking, 2002. Journal of Material Processing Technology, 2002, 122, pp. 338343. DOI: 10.1016/S0924-0136(01)01239-0

[5] Makich, H., Carpentier, L., Monteil, G., Roizard, X., Chambert, J., Picart, P., Metrology of the burr amount - correlation with blanking operation parameters, Int J Mater Form, 2008, 1, pp. 1243-1246. DOI: $10.1007 / \mathrm{s} 12289-008-0167-0$

[6] Hambli, R., Prediction of burr height formation in blanking processes using neural network, International Journal of Mechanical Sciences, 2002, 44, pp. 2089-2102. DOI: 10.1016/S0020-7403(02)00168-6

[7] Fang, G., Zeng, P., Lou, L., Finite element simulation of the effect of clearance on the forming quality in the blanking process, Journal of Materials Processing Technology, 2002, 122, pp. 249-254.

DOI: 10.1016/S0924-0136(02)00056-0

$\begin{array}{ll}\text { Submitted: } & 22.03 .2016 \\ \text { Accepted: } & 10.5 .2016\end{array}$
Çavuşoğlu

Hakan Gürün

Gazi University, Faculty of Technology, Department of Manufacturing Engineering, Ankara - Turkey onurcavusoglu@gazi.edu.tr, hgurun@gazi.edu.tr 